\title{
A gendered approach to drought-coping mechanisms: A case of the Lubombo region, Eswatini
}

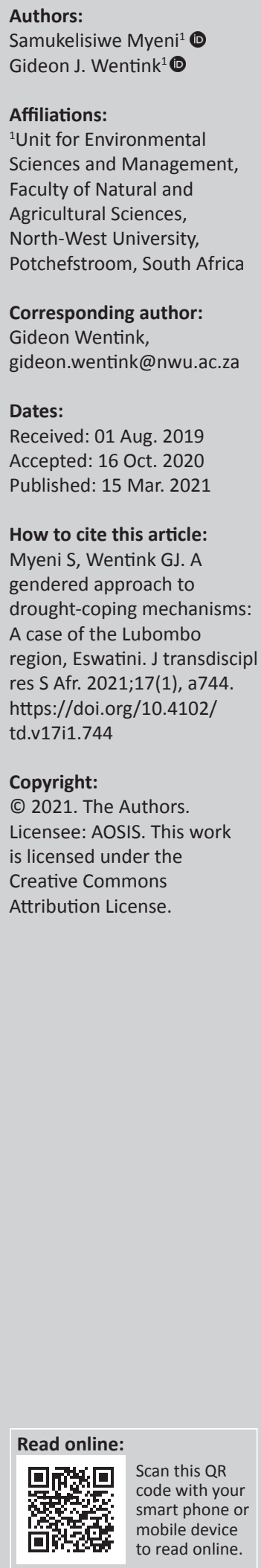

During periods of drought, coping mechanisms employed by society differ based on gender, and are related to socio-cultural implications. This study is premised on the gendered approach to drought-coping mechanisms by focusing on the manner in which communities undergoing drought adapt to the adversities experienced and thus employ gender-sensitive coping mechanisms. Socio-cultural implications emphasise and dictate the different gendered behaviour patterns within society. Thus, the purpose of this study was to determine and evaluate gender-differentiated coping mechanisms of withstanding drought used by communities in the Lubombo region of Eswatini. The exploration of this phenomenon utilised a mixed-methods approach to collecting data. This universal approach involved adopting both qualitative and quantitative techniques of gathering information to help in an in-depth analysis of the situation in the Lubombo region. Under the umbrella of mixed methodology, an exploratory sequential approach was used to collect data. The purpose was to allow findings from a qualitative phase to be developed and tested for wider application and validation using a quantitative approach. The collection tools used under the qualitative enquiry included semi-structured interviews, face-to-face interviews and a focus group. The information gathered was subsequently presented in a thematic manner to draw attention on the dynamics within coping mechanisms. Two sampling techniques were used: initial stratified random sampling (representing the population being sampled) followed by purposive sampling to specify population characteristics and thus locating individuals who match the characteristics. There were 179 respondents in the study, of which 83 respondents were part of the focus group discussions and the remaining 80 respondents engaged in self-completion survey questions. The gender spectrum of the respondents was uneven during the focus groups with 39 females and 44 males. However, during the self-completion survey questions, an even number of 40 males and 40 females participated. The gender gap observed displayed women as burdened with developing various coping mechanisms, whereas men solely adapted through seeking employment. Women's coping mechanisms included crop production, water management, foreign aid, sale of livestock and household functional change. In contrast, men's coping mechanisms involved migration and seeking employment. The disparities between men and women were observed as founded in cultural beliefs and practices as women tool a domestic role whilst men were tasked to be providers. This perspective directly impacts on the lines of vulnerabilities during drought, declaring women as the target population for social aid such as food packages from foreign aid and strong social capital. Through this study, culture and vulnerability were identified as risk factors contributing to the impact of drought forcing men and women to build and engage in mechanisms to alleviate the adversities experienced. The major recommendation of this study is that drought-prone communities need to build gendersensitive and gender-neutral coping mechanisms to withstand the adversities of drought.

Keywords: coping mechanisms; disaster risk management; drought; Eswatini; vulnerability.

\section{Introduction}

Drought is the most frequent natural calamity that affects Africa in comparison to natural calamities such as cyclones, earthquakes and fires. ${ }^{1}$ Drought is ranked highly amongst all natural calamities in terms of the number of people directly affected; with a total of about 642 drought events reported across the world during the period 1900-2013. ${ }^{2}$ The relationship between natural hazards and disasters is closely associated with the crisis situation in which the devastating event strikes. Thus, natural calamities play a defining role in the manifestation of disasters. The impact of disasters causes immense suffering, including disruption of livelihoods, loss of life, loss of

Note: This article is partially based on the author's thesis for the Masters dissertation completed in the Faculty of Natural and Agricultural Science, Unit for Environmental Science and Management at the North-West University, Potchefstroom, South Africa, under the supervision of Mr GJ Wentink and Mr LB Shoroma, received May 2018, available at: https://repository.nwu.ac.za/handle/10394/31280. 
financial stability and environmental degradation. ${ }^{3}$ In this regard, the magnitude of a disaster depends directly on the intensity of the calamity and the susceptibility of the exposed environment. $^{3}$ The dependency relationship between environmental shocks, economic stresses and human livelihoods has a direct bearing on a community's resilience and coping capacity. ${ }^{4}$ Evidently, the repercussions of drought have an enormous influence on the quality of life, economy and health of the environment it befalls. ${ }^{5,6}$ In addition, MataLima et al. ${ }^{7}$ specifies that understanding the relationship between calamities, disasters and the social impacts, thereof, addresses questions relating to adaptive capacities, social impact and survival. According to Singh, ${ }^{8}$ the impact of droughts is expected to grow over the years to come, affecting community livelihoods, aggravating poverty levels and impacting the sustainability of basic societal living. African countries, and particularly those within the southern hemisphere, have over the years been affected by severe and recurring droughts. ${ }^{9}$ Within Southern Africa drought occurs often and in all climatic zones at various times of the year. ${ }^{10}$ The region is characterised by strong inter-annual rainfall variability since the 1970 s and as a result is particularly vulnerable to drought. ${ }^{10}$ The impacts of drought on the subcontinent are aggravated by the fact that the region is dependent on rain-fed agriculture, foreign aid and water availability. ${ }^{11,12}$

The recorded history of drought in Eswatini as part of the Southern Africa region dates back to $1982 .{ }^{13}$ Since then, the most severe droughts have been felt in 1992, 2001, 2007, 2008 and recently in 2015. ${ }^{13}$ Droughts in the Lubombo region (located in north-eastern Eswatini) (see Figure 1) have occurred in different magnitudes, periods and areas. As an agricultural 'Haven', the Lubombo region is frequently faced with a constant risk in crop production, water scarcity, poverty, hunger and livelihood stability. ${ }^{14}$ In Eswatini, drought events have prompted livelihood shifts and triggered escalating vulnerabilities within communities..$^{15}$ Le Masson et al. ${ }^{16}$ caution regarding the importance of understanding the vulnerability lines between men and women in the midst of droughts including mobilising the community towards gender sensitivity. He further encouraged capacity-building strategies that are neutral between genders. Drought adds strain to the already fragile gender lines that exist in Eswatini. ${ }^{17}$ Traditionally, in Eswatini, women and men have well-defined roles and responsibilities. ${ }^{17}$ Women and girls in Eswatini are primarily responsible for domestic chores and care-giving, whereas men are described as bread winners and awarded power and rights. ${ }^{17}$ In this regard, during the occurrence of a drought, women and men are expected to function and perform distinct duties. These duties shape the livelihood mechanisms employed as a tool to cope with drought. ${ }^{18}$ Therefore, developing sustainable coping mechanisms to withstand the widespread effects of drought is challenged by the vulnerability measure of the communities in Eswatini. ${ }^{19}$ In this context, gendered disaster risk reduction (DRR) mechanisms that will help cope with extreme weather events are a stepping stone towards vulnerability mitigation.

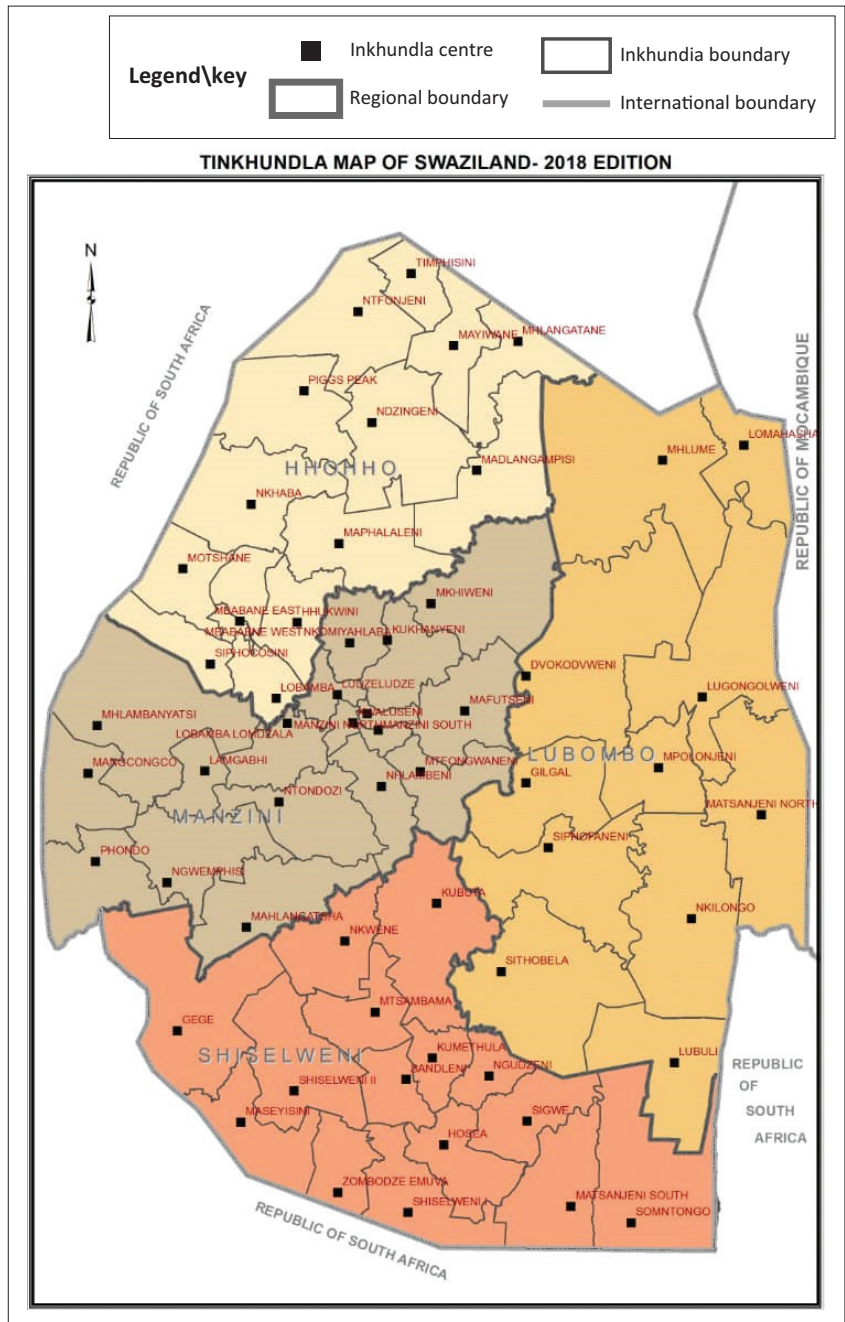

Source: Ministry of Tinkhundla Administration and Development (MTAD). Learn more about your Inkhundla [homepage on the Internet]. 2017 [cited 2017 Sep 21]. Available from: http://www.gov.sz/index.php/learn-about-your-inkhundla

FIGURE 1: Map of Eswatini.

However, a key challenge lies in the integration of these mechanisms and bridging the gender gap. ${ }^{20}$ Most of the global and national literature on Eswatini focuses on agriculture, drought, food insecurity and vulnerability alleviation..$^{21}$ There is a literature gap in DRR in relation to gender and culture. Thus, the gap in the empirical and theoretical literature pool, on crucial issues such as DRR, gender, culture and drought as both individual and interactive phenomena, needs to be bridged. Furthermore, this gap necessitates this study on the gender-differentiated coping mechanisms for adapting to drought used by prone communities in the Lubombo region. To address these gaps, limitations and the disparity between men and women during drought, the following article is necessitated. The need to develop and explore the gendered coping mechanisms in Eswatini is the primary focus of the study and is a means of integrating gender mainstreaming in DRR.

\section{Demarcation of study area}

The Lubombo region, in Eswatini, is populated by 300000 people of which $78 \%$ are considered poor and vulnerable. ${ }^{22}$ The Lubombo region is a pastoral region with an annual 
mean rainfall of $700 \mathrm{~mm}$ and an average annual temperature of $19{ }^{\circ} \mathrm{C} .{ }^{23}$ Agriculture provides livelihoods and income for $70 \%$ of the population of the Lubombo region, making the communities within the region dependent on produce. ${ }^{23}$ Consequently, the region is prone to weather-related calamities such as drought because of its dependency on rain-fed agriculture. ${ }^{24}$

Under the Lubombo administrative region, there are 11 regional councils called tinkhundla. ${ }^{25}$ An inkhundla (singular of tinkhundla) is an administrative sub-division, smaller than a district but larger than umphakatsi or chiefdom. ${ }^{26}$ The five regional councils that were included in the study are:

- Inkhundla Lomahasha;

- Inkhundla Mhlume;

- Inkhundla Mtsenjeni Nord;

- Inkhundla Mpolojweni and

- Inkhundla Sphofaneni

The map of Eswatini is displayed in tinkhundla and shows the parameters of each inkhundla which will be under investigation as well as the main administrative region (Lubombo), which is the case study.

\section{Problem statement}

Globally, the livelihoods of millions of men and women are at risk because of droughts. The risk incurred is different depending on whether an individual is male or female. ${ }^{27}$ The difference between the risk faced by the different persons based on gender emanates from social norms, practices and vulnerabilities experienced on a day-to-day basis within affected communities. ${ }^{9}$ As a result, men and women develop different means to cope with and implore different coping mechanisms to resist drought. The relationship between drought-coping mechanisms and gender is pronounced through the ability of men and women to rise above the existing repercussions of water scarcity and gender roles. ${ }^{28}$ Cultural beliefs and resulting social practices that support patriarchy reinforce the male dominance and female submissive behaviour in Eswatini. ${ }^{9}$ These cultural beliefs and practices around gender roles influence how men and women adapt to and mitigate drought and drought-derived disasters.

In the Lubombo region, one-third of Swazis live through the devastating impact of drought with significant effects on livelihoods and the environment. ${ }^{29}$ Because of recurrent drought events, the devastation of limited rainfall has affected all sectors in the Lubombo region, which has forced the population to engage in and develop coping mechanisms as responses to their vulnerabilities and impact to drought. ${ }^{30}$ Evidently, the implications of drought have a downstream effect that is dependent on the context and underlying population dynamics of the area. ${ }^{9}$ The struggle of living in a drought-prone region has inevitably made men and women eager to devise methods for protecting themselves and their livelihoods. In the face of a drought, or threat thereof, coping mechanisms are built based upon skills, technologies, resources, culture and experiences of men and women. ${ }^{31}$ The priority of building human capacity and alleviating the impact of drought on gender levels seeks to prioritise, build and create awareness of gender as an underlying issue towards the achievement of DRR in immediate societies where people dwell. ${ }^{32}$

According to Swaziland Vulnerability Assessment Committee, ${ }^{15}$ coping mechanisms are an essential component of how the Lubombo region attempts sustainability. The capacity to adapt and adjust to the adversity of drought is not the same between men and women. The coping mechanisms index used by the SVAC indicates that the different coping mechanisms between men and women are dependent on vulnerability associated with culture, roles, responsibilities and locality. ${ }^{15}$ The role of gender within the coping process of drought depicts the personal encounter of individuals and steps to be taken to ensure that DRR is achieved. Hence, the coping mechanisms that individuals engage in are directly dependent on gender (Mkhabela G 2016, [Women and drought in Mambane], personal communication, July 10). For example, in a patriarchal country like Eswatini, men and women have set roles that culture prescribes, thus awarding certain tasks to certain individuals. ${ }^{9,17}$ Mkhabela emphasises that surviving the disastrous effects of drought, women engage in practices that are separate yet domestic to men.

Building gender-focused mechanisms within drought-prone communities is a priority towards the achievement of DRR activities. ${ }^{33}$ Women have been identified by United Nations International Strategy for Disaster Reduction (UNISDR) as being more exposed than men to disaster risk, suffering mortality, morbidity and damage to livelihoods. ${ }^{33}$ This premise generates the foundation of this study, determining the different coping mechanisms employed by men and women in the Lubombo region. The problem under study will further be explored by addressing the research questions.

\section{Research objectives}

The main objectives of the study were to:

- Provide a theoretical overview of the impact of drought on communities.

- Provide theoretical perspective of gender mainstreaming in DRR.

- Analyse drought-coping mechanisms employed in Lubombo, Eswatini.

- Determine the value of gender coping mechanisms within the Lubombo region.

- Provide conclusions and recommendations on the gendered approaches to coping with drought in the Lubombo region, Eswatini.

\section{Theoretical perspectives on drought}

As a recurrent climate phenomenon, drought affects humanity in many ways including the loss of life, crop failure, livestock loss, famine, malnutrition, health issues and mass migration. ${ }^{34,35}$ Additionally, drought is dependent on 
the geographic scales, severity and the intensity of the affected area. ${ }^{36}$ The southern African region has been heavily affected by livelihood changes resulting from severe drought. ${ }^{37}$ Subsequently, drought becomes a disaster once it produces social, environmental and economic impacts that are above the means of coping within communities. ${ }^{38}$

During a drought, communities practise and adopt strategies aimed at building capacity to enable coping with drought impacts. ${ }^{39}$ Additionally, the behavioural choices during a hazardous event are shaped by the interpretation of the hazard, as well as the need to survive the event. ${ }^{40}$ Variety in community arrangement contributes extensively to the ability to adopt and build coping mechanisms. ${ }^{41}$

Men and women in disaster-prone communities are challenged with building different levels of coping mechanisms towards existing hazards and the damaging effects of the hazard occurrence. ${ }^{18}$ Understanding this echoes the problem statement and position that men and women are differently affected because of the socially constructed roles and responsibilities. ${ }^{33}$ Since the level of exposure differs on gender lines, unsafe conditions for men and women are generated, calling for a need to survive, grow and understand how drought-resistant capacity can be built. ${ }^{18}$

\section{Drought-coping mechanisms}

The primary means by which populations cope with drought are found within community, household and individual mechanisms that act to safeguard against drought-related losses. ${ }^{42}$ It is for this reason that UNISDR ${ }^{43}$ defines coping strategies as the manner in which people and organisations use existing resources to achieve various beneficial ends during unusual, abnormal and adverse conditions of a disaster phenomenon or process. Gaillard ${ }^{44}$ emphasises that coping mechanisms are rooted in resources which are endogenous to the community, such as traditional knowledge, systems and skills, technologies and solidarity networks. Coping mechanisms further relate to resources and assets available to individuals and societies to enable them in dealing with, and recovering from the impact of, hazardous incidents and disaster shocks. ${ }^{45}$ For example, the impact of a drought can affect and change societal beliefs, customs, social organisations like gender, attitudes and values. ${ }^{46,47}$ Droughts have over the years haunted arid and semi-arid communities, forcing them to change or to mitigate shocks and stresses on their livelihoods by building temporary adjustments as response. ${ }^{48}$ Adaptation and coping practices are necessary to reduce vulnerability to drought stress as well as to prepare for future extreme weather variations. ${ }^{49}$

\section{Theoretic perspectives of gender}

According to Nelson, ${ }^{50}$ gender lines in society present the relationship between vulnerability, environmental change and the interaction between the societal standing of men and women. Vulnerability associated with women's or men's identification accentuates inequalities in society through the disproportional exposure of individuals to risk and hazards. ${ }^{51}$ Hummell et al..$^{52}$ posit that the difference in human capacity to prepare for, respond to and recover from drought is dependent on social vulnerabilities, social constructs, power dynamics and the roles of men and women. The value of bridging the gap between gender and disaster risk within a community is to ensure that capacity between men and women is built. ${ }^{43}$

According to Eckert and McConnell-Ginet, ${ }^{53}$ gender lines exist in the general functioning of societies. The lines of gender are found in institutions that provide direction for society and also the actions of men and women along with their beliefs and desires. ${ }^{53}$ Based on a report compiled by $\mathrm{UNESCO},{ }^{54}$ in nearly all societies, men and women behave differently, dress differently and have different attitudes and interests. These differences found between men and women are not biologically or genetically determined, rather they are socially constructed. ${ }^{55}$ From a tender stage in human growth, both men and women are moulded through socialisation within the community, emphasising a humanity split through actions, performances and duties. ${ }^{56}$

\section{Gender and disasters}

Disasters affect social groups differently and to different degrees. ${ }^{33}$ During a talk on Women, Disaster Reduction and Sustainable Development, the UNISDR Secretariat ${ }^{20}$ said:

Both women and men are part of the same society, which, as we know, does not mean we have the same rights, education, and options to manage, neither in 'normal' times, nor when a disaster strikes. (p. 1)

The occurrence of disaster in society is a consequential challenge of the established roles and stereotypes imposed on men and women. ${ }^{16}$

According to Enarson and Chakrabarti, ${ }^{27}$ the magnitude of disasters on gender demands the need for establishing and practising gender sensitivity towards analysing disasters and building DRR policy and practices into the promotion of building a culture of safety. As an extension of encouraging gender sensitivity at the national level, policies like the Sustainable Developmental Goals, the Sendai Framework for DRR and the Paris Agreement on Climate Change are enacted and adopted to ensure adherence to gender-sensitive DRR.

\section{Methodology}

The research process was guided by the principles of conducting mixed methodology research. Creswell ${ }^{57}$ describes mixed methodology as the collaboration of qualitative and quantitative data to yield in-depth understanding of a phenomenon or field of knowledge. In this study, mixed methodology research was conducted through exploratory sequential design. ${ }^{58}$ More specifically research was conducted using three phases. ${ }^{57}$ During phase 1 , following a review of the literature available on gendered coping mechanisms of drought in the Lubombo region, data 
were collected through focus group discussions. This information was used to creating themes as foundation of participant's perspectives, validating the instrument with a large sample representative of the Lubombo region inhabitants. Collecting this data qualitatively establishes the impacts of droughts on communities, including integrating and mainstreaming gender in DRR. For phase 2, selfcompletion survey questions were administered to participants in all five tinkhundla to establish the droughtcoping mechanisms employed in the Lubombo region as well as, to confirm the information given by the respondents in phase 1 quantitatively. Lastly, phase 3 was an integration enquiry, where data gathered from both qualitative and quantitative enquiries were combined to determine what the gendered coping mechanisms employed in the Lubombo region are, and secondly achieve the desired outcome of highlighting the need for gender equity and sensitivity in policy and during disasters in Eswatini.

In this study, stratified random sampling that is proportional to the population was used first to represent the qualitative enquiry. Under the Lubombo region, five regional councils were selected, and two focus groups were conducted in each. The focus groups were separated by gender, where 44 male and 39 female respondents were engaged. This was followed by purposive sampling to specify characteristics of the population under study and thus locate individuals who match the characteristics. ${ }^{59}$ Eighty respondents were approached for a purposive sample as part of a selfcompletion survey question. There were 16 surveys completed per regional council. This makes a complete sample size of 179 respondents, all answering the broad topic of gendered differentiated drought-coping mechanisms in the Lubombo region. Beginning with phase 1 and using themes, this topic will be explored further.

\section{Perception of drought}

According to Taylor et al., ${ }^{60}$ the word 'perception' refers to beliefs, judgements and attitudes one has towards something. During a drought, the perception of the inhabitants of the Lubombo region is shaped by the experiences they face. This observation is validated by Dessai and Sims ${ }^{61}$ that during a drought, the characteristics of a dry spell and the experiences thereof influence the judgements, beliefs and attitudes of communities. This necessitated the understanding of drought from a gendered lens as the core of this paper. Derived from the qualitative data collection, drought was defined through various synonyms by the respondents. Numerous times respondents said, 'somiso indlala yodvwa, kute emanti, kumaima kulima' [drought means hunger, no water and farming is a serious challenge]. In the Lubombo region, the dependency on agriculture fostered the response that amongst hydrological, meteorological, socio-economic and agricultural drought, the most relevant for the region was agricultural drought. As an agricultural sanctuary, farming industries harvest sugar and cotton whilst households rely on subsistence farming for survival. Respondents qualified this stance by saying, 'laLibonjeni silambhile kakhulu, siphila ngekusebenta emobeni,sibe bomagawulane tsine emadvodza nekulima ke lowentiwa bomake. Nakhona litulu nalivumile, ngoba emanti kute' [in the Lubombo region we are very hungry, we depend on the sugar industry to employ us, men as cane cutters and women as planters. There is a strong dependency on water that makes farming difficult]. The respondents further agreed that agricultural drought and the lack of soil moisture amounted to a drought. Of the men within five inkhundla administrations, $10.3 \%$ stood by this definition, and were supported by $17 \%$ of women in the region. More men (33\%) than women $(30 \%)$ believed that an agricultural drought was mostly experienced in the region because of soil moisture and crop planting constraints.

Figure 2 on water shortages during drought displays the relationship between water and livelihood shift of men and women in the Lubombo region. Water is the core and was deemed as such by both men and women equally. In Lubombo, respondents' conceptualisation of drought was defined as comprising water shortages and insufficient food by both men and women at $72 \%$. On an average scaling, $25 \%$ of both women and men were of the opinion that water shortages described a drought period.

In addition to defining drought as water shortage, respondents were of the opinion that during a drought hunger is rife and food resources perish. Statistically, a majority of $77.5 \%$ of women voiced this stance strongly and only $65 \%$ men strongly agreed. The responses of the community members advocate that the relationship between water availability and food availability is challenged during a drought as communities depend significantly on these commodities (see Figure 3).

\section{The impact of drought}

Socio-economic impacts of drought can be viewed at macroand micro-levels. Macro-level involves the economy at a large-scale (country and regional) level, yet micro-level is that which affects the community, household and individual. Because of the scope of the study, the focus will be on microlevel as a tool to inform the macro-level. During the study, it was revealed that at the community level, the livelihood

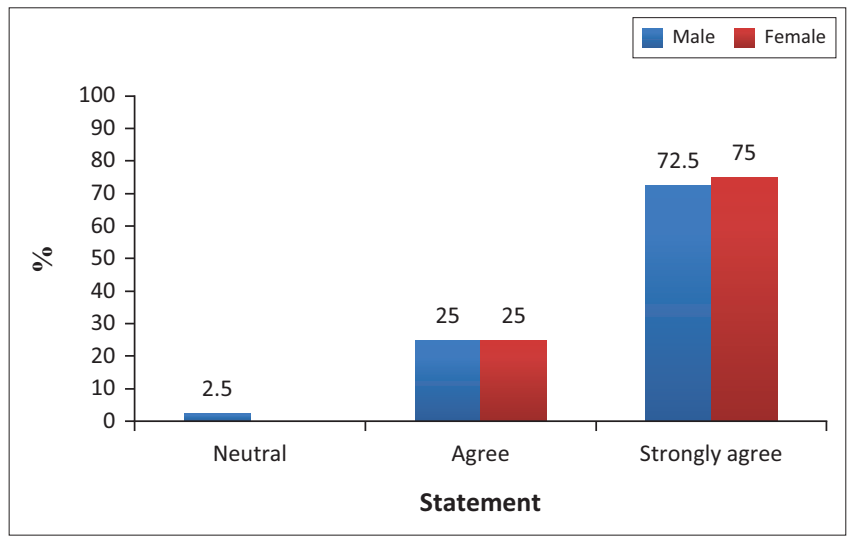

Note: The definition of drought is comprised of water shortages and insufficient food. FIGURE 2: Water shortage during drought. 


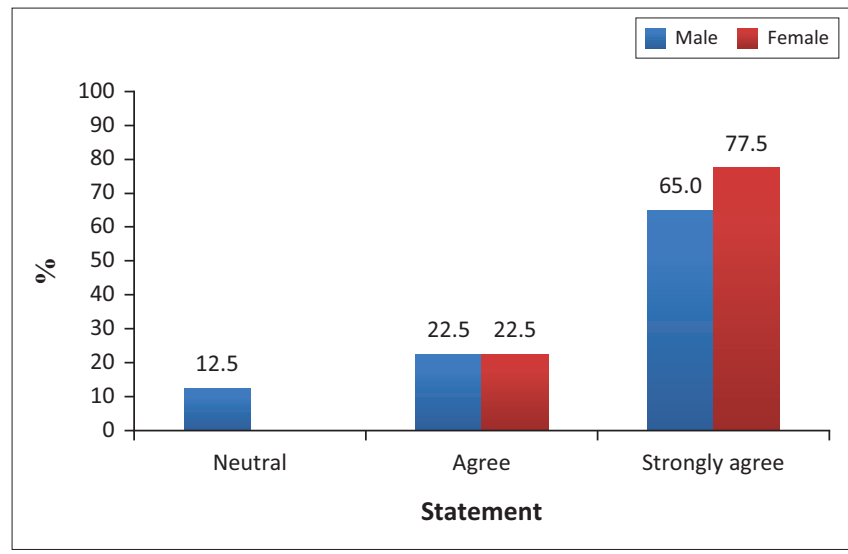

Note: During a drought hunger is rife and food resources perish.

FIGURE 3: Drought food insecurity.

source is vastly affected by a drought, particularly crops, livestock and labour. ${ }^{62}$ In the Lubombo region, 70\% men expressed a significant lifestyle change opposed to $30 \%$ women. Women participants expressed that 'Lesimo sesisijwayele, kwamele sente taba tekumelana naso somiso hhayi kubaleka njengemadvodza etfu' [we are used to this situation; we have to adapt through coping mechanisms rather than leave like our men].

The Lubombo region is an agricultural hub, dependent on rain-fed farming systems. Of both male and female respondents, $98.7 \%$ emphasised the drought impact to be recurring and yearly. Cropping systems are therefore changed to withstand the drought adversities and avert production loss. An example was expressed by women farmers as collecting cow dung and using it as alternative fertilizer and floor polish ('Tsine bafati siyanidza etinhlini siphindze sakhe umcuba entinsimini ngebulongo'). Men gave an example of recycling two-litre bottles and using them as a drip system as part of water management ('emadvodza akha tindlela tekwonga emanti njegekusebentisa tigubu, tekunisela tinsimu noma tibhidvo'). To the detriment of the livelihood and nutrition of families, the change in production level threatens food security. When asked about food security during drought, women responded that hunger is rife and food resources perish ('indlala siphila nayo ne kudla kuyaphela'). A majority of $77.5 \%$ women voiced this stance as opposed to the $22.5 \%$ men who agreed and were indifferent. This food availability measure further displays the gender lines within households as women are culturally tasked with manning the household compared to men who are traditional providers of the household. Consequently, women are more aware of food availability compared to men.

This research has determined that livestock in the Lubombo region represents wealth and food security. Severe livelihood changes have been identified by respondents as compelling the liquidation of livestock and agricultural products. The occurrence of a drought undermines this livelihood pattern, forcing inhabitants to liquidate livestock in exchange for food and money. ${ }^{63}$ This is not an easy process for men, as culturally men are characterised by having cows. To emphasise this point, the respondents referred to livestock as 'Libhange lemaSwati' [the bank of the Swazi nation]. Eighty per cent of the men questioned about livestock's impact of drought expressed psychosocial repercussions of watching their animals die from hunger. Male respondents expressed that besides selling livestock, the frequency of Lobola ceremony was rising. Male respondents described that as the prices of cattle dropped, men ready to take a wife would buy cows to pay lobola for their girlfriends ['somiso sifika netimanga, emadvodza ayalobola entele kungalusi futsi kuhambisa imfuyo ngoba iyashipha kani kuyondla kumatima'].

According to Kreimer and Arnold, ${ }^{64}$ coping with the economic impact of disasters is associated with the allocation of funds for assistance and understanding the financial abilities of a community. During a drought, there is a close association between fluctuation of food, prices and unemployment. The respondents highlighted the fact that food prices soar during a drought, for example, the price of cooking oil increased by E20. This forced various communities within the Lubombo region to sell assets such as livestock, vegetables and conduct services like domestic work and prostitution. 'Etitolo konkhe kuyadula, kuvele kukhushulwe emaprice ngenca yekusti sonkhe sesiyatsenga, ngibekise emafutsa ekupheka abita bo E80.00 kantsi singakangeni somiso bekabita E55-60'. Of the male respondents, $85 \%$ have jobs, whereas $72.5 \%$ of females are employed. Seeking work has become a reality in the Lubombo region, especially because a single income is not sufficient to run a household. There is still a dependency behaviour among women towards men and they receive money from men. A majority of women $(77.5 \%)$ receive money from someone other than an employer, as opposed to $22.5 \%$ of men. Money is received from various individuals and organisations during a drought. During the collection of data, it was discovered that women $(54 \%)$ received more money from the immediate family than men do. Statistics continue to highlight the fact that men received the lowest amount of money from immediate family and relatives; however, government grants are received by more men than women. The amount received by men from the government is an annual grant of E2640. ${ }^{18}$

Socially, the livelihood impact of drought includes cultural change and changes to gender dynamics within the community. In the Lubombo region, people migrate to other towns, especially those next to industries and plantations as a means of searching for employment. The towns targeted are Big Bend, Mhlume and Tabankhulu. Respondents mentioned that these towns have sugar plantations and employ most men as cane-cutters and women as sugar planters ['kuze sitfole imali sisi, sihamba siyosebenta ehlandzeni kasugela simadvodza, sishiye imindeni nebantfwabetfu ngoba kuhlalwa emahostela']. Despite this, the majority of the respondents identified that migration was a coping mechanism used by men as a consequence of cultural and societal roles as being financial providers of households. In addition to migrating for financial gain, men also migrate to search for livestock feed and water, through buying livestock 
land and the Kukhonta system (i.e. traditional land acquisition, allocated by chiefs). Migration is not perceived as a positive coping mechanism because family structures are torn apart when men never return home. Additionally, once the men migrate, women are forced to rise above cultural constrains and become providers for their households in the absence of their husbands. The respondents explained that women assume the roles of men during droughts, resulting in females becoming heads of families ('nakasishiya emadvodza etfu kusala kubona tsine sibomake'). Drought continues to undermine culture, forcing some practices such as keeping livestock, water management being solely women-oriented and women not having jobs paying more than men to be abandoned.

Social capital is also affected during a drought. Social capital and trust relationships in society are very important and valuable for increasing society's livelihoods, standards of living and social welfare of a community. ${ }^{65}$ In the Lubombo region, social support is important and made up of neighbours, relatives, government, foreign aid, nongovernmental organization (NGO) and household members. The respondents, both men and women, agreed that 'umuntfu akalakhi likhaya ayedvwa' (individualism is not accepted because no one can live alone or be an island). Oddly, in the event of a drought disaster, $72.5 \%$ of men and $87.5 \%$ women respondents felt supported by the community. Coping mechanisms in terms of social capital in the Lubombo region involved assisting one another with food sample donations from NGOs, borrowing of livestock for farming, food sharing, gifting and loaning of money and helping physically to plough fields of those who have lost cattle. Social capital is thus a pivotal disaster reduction strategy aiming at mitigating the adverse impacts of disasters. Social capital is depicted in the statistics above as necessary towards reducing the social impact, networks and influences as a form of coping mechanism. The burden of vulnerability and impact is lightened, when community unifies and acts in solidarity, this position stems from the pressure and release framework. This model is a tool of analysis, which shows how disasters occur when natural calamities affect vulnerable people. ${ }^{66}$ In addition, Singh ${ }^{8}$ points out that the Pressure and Release Model (PAR) depicts disaster as a product of physical exposure and socio-economic exposure by distinguishing between root causes, dynamic components and unsafe conditions as conditions of the manifestation of a disaster. Adaptation and coping practices are necessary to reduce vulnerability to drought or hazard stress as well as to prepare for possible future extreme weather variations. ${ }^{49}$

Coping mechanisms are a stepping stone towards evidence of DRR within the Lubombo region. These coping mechanisms are, however, challenged because some community members become self-centred. A traditional Swazi saying was used numerous times during the research data-gathering stage: 'Gubela kwesakhe' [focusing on oneself and ignoring anyone else]. Eight per cent of men explained that during droughts community members are unwilling to share, hogging all food and job opportunities for themselves and their relatives.

\section{Gender-differentiated roles during drought}

The results of this study show that both men and women living in drought-stricken Lubombo region adhere to cultural roles and deviate against them only when necessary. $\mathrm{FAO}^{67}$ identifies a gender gap between men and women in relation to disasters such as drought and highlights that gender roles perpetrate differentiation and inequality. The findings of the study further reveal that a large majority (97\%) of male respondents believe that men and women have different roles and responsibilities to fulfil during drought. An affirmative response of $92 \%$ women respondents also agreed when asked about the differences in roles and responsibilities. In addition, men mentioned that 'kulisiko kuhholwa ngubabe noma indvodza' [it is culture to be led by a man rather than a women]. Women emphasised this position by stating that 'lusiko nenkholo iyahlukanisa emisebentini netindlela tekuphila tamake na babe, siphila ngalokuhlukanisa' [culture and religion are guiding principles of the way of life, society abides by the fact that men and women are separate with separate roles and responsibilities]. Based on the differentiation of roles, the respondents affirmed that gender determines the power relations in a household. This position was affirmed by $95 \%$ male respondents.

Gender-differential roles during drought reflect the resources associated to men and women by displaying that men have better opportunities over women. For example, 97.5\% men and $92.5 \%$ women have agreed that, regardless of the situation or disaster, men continue to be heads of the household and women continue to manage the domestic responsibilities of the household. Despite this cultural implication, men however felt burnt out as they have to continue taking the leading role during a drought and not deviate from being providers. Men expressed ' $k u b a$ yindvodza, khonkhe kufunwa kuwe khani nawe usazama kuhlanganisa. Labomake babheke tsine' [it is tough being a man; all is needed from us men. Our wives depend on us]. The dependency women attach to men indeed does not subside unless the man is not around. Women felt that 'imali yababe ayipheli' [a man or father's money doesn't finish]. Thus, during a drought, men experience psychosocial challenges of which women and culture implications do not acknowledge. On the other hand, women are burdened by culture differentiation. Women are generally described as their husbands' first child. ${ }^{68}$ This sets the tone for women's activities in the community, forcing women to only participate in activities or duties dictated by their husbands. Seventy per cent of the women attested to this stating that during community meetings women do not have legal standing and thus entrust all coping mechanisms or drought awareness initiatives to be presented publicly by male counterparts ['bafati bayayihlonipha indvodza futsi bangephansi kwayo ngaso sonkhe sikhatsi.kungako sisi ngisho emphakatsi bafati abakhulumi balalela kuphela'].

\section{Drought-coping mechanisms}

Drought-coping mechanisms serve as activities and a tool that the community uses to manage the situation. Several 
coping mechanisms were found to be practised in the Lubombo region to minimise the effects of drought such as migration, drought relief scheme (foreign aid), crop management, water management, sale of livestock and household activities.

\section{Migration}

Drought-affected families migrate to other areas to seek income-producing employment that can help them to survive the adversities of drought. In the Lubombo region, people migrate to other towns, especially those next to industries and plantations as a means of searching for employment. The towns targeted were Big Bend, Mhlume and Tabankhulu, and respondents mentioned that these towns have sugar plantations and employ most men as cane-cutters and women as sugar cane planters. Despite this, the majority of the respondents identified that migration is a prominent coping mechanism used by men to fulfil their societal role of being 'bread winners' and financial providers of their households.

Statistically, livelihood breakdown is evident in migration $(43.59 \%)$. The separation of families is a form of generating income, yet leaves the family unstable and forced to adapt to change. Women are forced to assume traditional male roles $(30.77 \%)$ like herding the cattle and looking for work to supplement the financial situation of men. Migration has been identified as a practice rather performed by men than by women. Men also migrate to search for livestock feed $(7.50 \%)$ and water (5\%), by buying livestock land through the Kukhonta system. Women on the other hand migrate to escape from home conflict $(2.5 \%)$ and the frustration of not having enough water and food. Respondents concluded that migration is necessary but undermines the livelihoods of the community, with $43.6 \%$ of both men and women concurring with this view.

\section{Drought relief schemes}

To better cope with drought, households received help from beyond their communities. ${ }^{69}$ The support received was drought relief, by the government of Eswatini, supported by United Nations and development partners known by locals as 'Tinini Tenkhosi' [The Kings Friends]. Assistance was in the form of cash, food, seed and fertilizer.

Organisations such as USAID, Red Cross, World Food Programme and World Vision assist with food rations once a month, which is used by women to feed their families and curb hunger in the households. On the other hand, men are given training to build their capacity. The trainings received equipped men with coping strategies such as eating twice a day, using animal waste as manure for crop production, dividing food among days and using bath water to irrigate plants and vegetables.

According to the information gathered from the government officials, the field of DRR is new in the country. The growth of the field is drawing attention on the varied behaviour and methods of coping that men and women follow. Government officials further acknowledged the fact that women are target population during a disaster such as a drought, thus imposing interventions that begin with assisting women. They justified this approach by stating that 'bafati beswele Kanye nebantfwana kahkhulu, kwengca emadvodza. Loku akusho kutsi emadvodza asiwanaki kopha sibuka simo' [women and children are most vulnerable. It does not dispute the vulnerabilities of men; however, assistance is a situational approach]. This perpetrates the topic of this study and enforces the need for gender sensitivity and equity practices at all times.

\section{Crop management}

The survey data showed that drought affected crop production greatly and enforced inhabitants of the Lubombo region to engage in comprehensive crop management mechanisms. Agricultural adjustment was practised by all community members as $100 \%$ men and women indicated that they practise crop replacement during a drought. This activity involves cultivating more water-efficient crops.

Crop production in the Lubombo region is very important for the stability of livelihoods and for food security. During a drought, men and women plant and grow crops that should withstand the grave dry conditions. The women are in charge of weeding and management of the crop. Women plant nuts, cassava and sweet potatoes as substitute for maize starch. They eat natural shrubs and weeds such as Ligusha (Corchorus olitorius), umbhidvo [shoot] and inkhakha (Mormodica balsamina). These greens are healthy and full of nutrients, helping them maintain a healthy diet. Male coping mechanisms relating to crop production include men hiring trucks and driving them to prepare the fields for production.

\section{Water management}

Water management is an essential part of ensuring that drought alleviation occurs. During droughts, water scarcity within the community, in particular rural areas, threatens the livelihoods of individuals. ${ }^{70}$ People depend on water for survival, hence the respondents indicated that water management coping mechanisms are developed and applied to withstand and adapt to the scarcity ('emanti ayongiwa, alandzwa khashane futsi amucoka,Senta siciniseko kutsi asiwadlabhatisi'). The respondents further discussed that water management is practised through activities such as regulating domestic water usage, regulating water to fulfil basic household activities, separating water gathered by quality, either for consumption or for cleaning and watering plants.

The role of women in water management involves collecting water, fetching water from rivers, ensuring that water is not used in wasteful ways, ensuring that children are bathed once a day and not twice, only using it for drinking and ensuring that enough water is available every day. Men on the other hand do not employ water management as a coping mechanism because water management is done mainly by 
women. Women also described that during drought seasons, local water pumps overflow with people queuing to fill buckets and 25-litre tanks. Because of the high volume numbers of people, some individuals come home emptyhanded without water. This process forces households to collect river water and purify it using traditional methods of purification such as the use of bleach (JIK) and cleaner (Dettol) ['basifundzisile kutsi emanti asemfuleni singawahlanta, basifundzisa kutsi sibowafaka I JIK noma DETTOL bese siyawayekela athule singakawasbentisi']. The purifying ratio is 1 teaspoon of disinfectant for every 25 liters of water and leaving it to settle for a full day. The respondents mentioned that this makes river water consumable ['emanti emfula abese ayanatseka']. A balanced opinion of $60 \%$ between men and women respondents attested to the fact that water management at the household level was predominantly women based with day-to-day activities.

\section{Sale of livestock}

During a drought, community members were challenged with disposing assets like livestock because of the lack of water and animal feed. The sale of livestock is a difficult coping mechanism to implement. Men are in charge of the livestock and thus have a wealth-based attachment to cattle, goats and poultry. This is advocated by the saying which states that a man is judged by his herd size. The selling of livestock allows a household to get money, food or services. Food stock and household expenses were said (60\% both male and female respondents) to overwhelm families forcing them to sell assets to raise money to buy food.

The dominance in the sale of livestock was also highlighted by a minority of men. The frequency of marriage proposals and dowry (lobola) ceremonies was said to be the reason for the growing number of cow sales during droughts. Ninety per cent men respondents expressed the fact that as the prices of cattle dropped, men ready to take a wife would buy cows to pay lobola for their girlfriends.

\section{Household activities}

Household coping mechanisms are the day-to-day coping mechanisms that a community and household implement. The households within the Lubombo region have been identified as following practices such as skipping meals to save food. Respondents mentioned that 'kudla kuyongiwa, labadzala badla kancane kunebantfwana' [food is scarce so we share among the family, children eat more than adults]. Children eat first and adults share food, reducing the portions of food being eaten. Bathing once a day and not at all on weekends, cooking outside to save electricity or the expense of buying electricity, switching on the necessary lights at night only, collecting wood and selling it to neighbours in exchange for food and money, doing laundry for others in exchange for food and saving money for essentials are some of the coping mechanisms followed. Other adopted coping mechanisms during drought included back yard gardens and selling vegetables, working as casual laborer (men as cane cutting at sugar belt), selling of livestock products such as milk, and maas (sour milk), little use of credit, kunanisa [borrowing from neighbors], sales of personal items, selling of household items (furniture) and prostitution.

At the household level, the coping mechanisms are practised and enforced equally between men and women. There were some instances, like fetching water, where men and women do work together; however, these instances are more supportive towards women. Fifty per cent men added that men will drive tractors to carry water for women from the river at times. Thus, men have been identified to help women when roles get overwhelming but not as a primary duty.

\section{The occurrence of agricultural drought in the Lubombo region}

In the Lubomboregion, the dependency on agriculture fostered the response that amongst hydrological, meteorological, socio-economic and agricultural drought, the most relevant for the region was agricultural drought.

This graph validates the recurring conversation in the study. The graph displays the contribution and perspective of drought on agriculture by both men and women.

As an agricultural sanctuary, farming industries harvest sugar and cotton whilst households rely on subsistence farming for survival. The respondents all agreed that agricultural drought and the lack of soil moisture amounted to a drought. At a neutral level, an agricultural drought occurs in the Lubombo region because the soil loses moisture, which results in making crop planting impossible. Within five inkhundla administrations, $10.3 \%$ of the men stood by this definition and were supported by $17.5 \%$ of women in the region (see Figure 4 ). The number of individuals who agreed with the definition included more men $(33.3 \%)$ than women $(30 \%)$.

In light of the definition of an agricultural drought, respondents were questioned on the impact of drought on crop production and community's livelihoods. The responses indicated that drought causes a significant decline in the availability of agricultural produce thus causing a livelihood

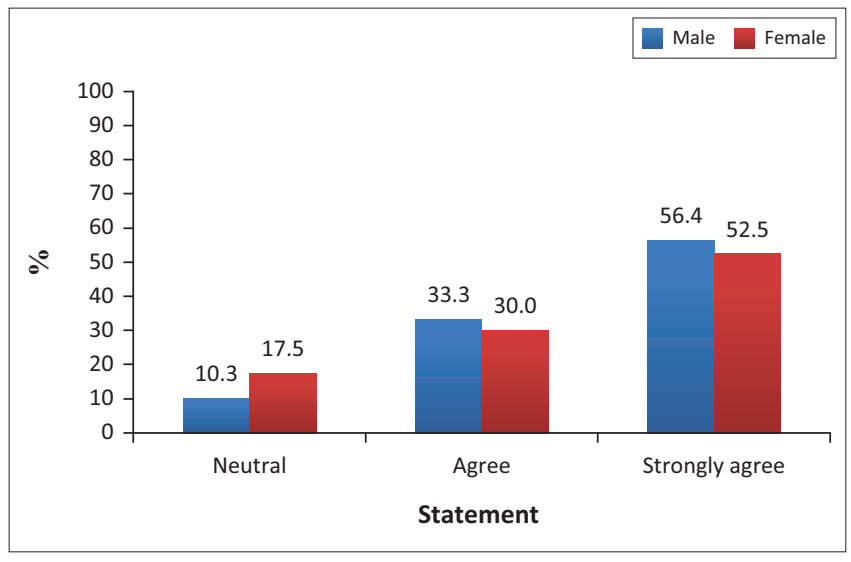

Note: An agricultural drought occurs because the soil loses moisture which results in making crop planting impossible.

FIGURE 4: Drought impact on agriculture: Absence of soil moisture. 
loss. Also, $98.75 \%$ of the respondents indicated that the magnitude of the drought is experienced every second year because of the region being arid. Respondents further said that 'njalo njalo kune somiso, siyehluleka kulima nekudla site' [the region struggles with the recurrence of drought and the inability to farm that comes with the calamity].

Subsistence dry land farming provides livelihoods for $70 \%$ of the population in the region. The occurrence of a drought undermines this livelihood pattern, forcing inhabitants to liquidate livestock in exchange for food and money. Respondents also highlighted the fact that because of the close proximity with the sugar band (Tabankhulu, Mhlume, Simunye sugar estate), during a drought subsistence farming is minimal because land is rather rented out to sugar companies as they have irrigation means and resources.

\section{Social capital and developing disaster risk reduction practices}

Social capital and trust relationships in society are very important and valuable for increasing society's livelihoods, standards of living and social welfare of a community. ${ }^{65}$ Social organisations such as networks, norms and social trust within a society allow individuals to work together and achieve mutual benefits. ${ }^{65}$

In the Lubombo region, social support is important and comprises neighbours, relatives, government, foreign aid, NGOs and household members. In the event of a drought disaster, $72.5 \%$ of men respondents felt supported by the community whilst $87.5 \%$ women felt that support from the community was evident. Coping mechanisms in terms of social capital in the Lubombo region involved assisting one another through food sample donations from NGOs, borrowing of livestock for farming, food sharing, giving and loaning of money and helping physically to plough fields of those who have lost cattle. These coping mechanisms are a stepping stone towards evidence of DRR within the Lubombo region.

\section{Contribution of gender in effective disaster risk reduction}

Vulnerabilities are associated with women more than men because of culture and lack of opportunity. Respondents highlighted this position by showcasing that during drought women's traditional duties do not change; duties such as reproduction, household maintenance and agricultural production strain women during a drought. The findings of the study reveal that a large majority (97\%) of male respondents believe that men and women have different roles and responsibilities to manage during drought. An affirmative response of $92 \%$ women respondents also agreed when asked about the differences in roles and responsibilities as reflected in Table 1.

Based on the differentiation of roles, the respondents affirmed that gender determines the power relations in a household. This position was affirmed by $95 \%$ male respondents. Table 1
TABLE 1: Gender-differential roles during drought.

\begin{tabular}{|c|c|c|c|}
\hline Statement & Variable & Male (\%) & Women (\%) \\
\hline \multirow{2}{*}{$\begin{array}{l}\text { Women and men } \\
\text { have different roles } \\
\text { and responsibilities }\end{array}$} & Yes & 97.5 & 92.0 \\
\hline & No & 2.0 & 2.0 \\
\hline \multirow[t]{4}{*}{$\begin{array}{l}\text { Roles of men and } \\
\text { women }\end{array}$} & $\begin{array}{l}\text { Agriculture activities } \\
\text { for income purpose }\end{array}$ & 5.1 & 2.7 \\
\hline & $\begin{array}{l}\text { Cash crop production } \\
\text { and subsistence farming }\end{array}$ & 5.1 & 2.7 \\
\hline & $\begin{array}{l}\text { Water use and } \\
\text { management }\end{array}$ & 2.6 & 2.7 \\
\hline & $\begin{array}{l}\text { Livestock management } \\
\text { (cows: men; poultry: } \\
\text { women) }\end{array}$ & 10.3 & 0.0 \\
\hline \multirow{5}{*}{$\begin{array}{l}\text { The patriarchal } \\
\text { nature of your } \\
\text { community }\end{array}$} & Not at all patriarchal & 0.0 & 2.5 \\
\hline & A little patriarchal & 45.0 & 37.5 \\
\hline & Unsure & 7.5 & 7.5 \\
\hline & Somewhat patriarchal & 30.0 & 32.5 \\
\hline & Completely patriarchal & 17.5 & 20.0 \\
\hline \multirow{2}{*}{$\begin{array}{l}\text { During drought } \\
\text { women continue to } \\
\text { do domestic work }\end{array}$} & Yes & 100.0 & 100.0 \\
\hline & No & 0.0 & 0.0 \\
\hline \multirow{2}{*}{$\begin{array}{l}\text { During drought } \\
\text { men viewed as } \\
\text { head of family }\end{array}$} & Yes & 97.5 & 92.5 \\
\hline & No & 2.5 & 7.5 \\
\hline
\end{tabular}

displays the gender-differentiated roles during drought. It reflects the resources associated with men and women by displaying the fact that men have better opportunities compared to women. For example, 97.5\% men and $92.5 \%$ women have agreed that, regardless of the situation or disaster, men continue to be heads of the household and women continue to manage the domestic responsibilities of the household.

\section{Conclusion}

The study has established that coping mechanisms are essential towards the alleviation of the effects caused by drought. From the results, the vulnerabilities of men and women have been identified as contributing factors to risks associated with being a community member in the Lubombo region. The coping mechanisms identified in the study include migration, foreign aid, cropping systems during drought, water management, sale of livestock, government departments and NGO aid and household activity changes. Gender relations have also been identified in this study as key contributors to the opportunities and constraints experienced in a community. Culture has been identified as the central mandate, prescribing rules, roles, norms and responsibilities to men and women. The interactions of coping mechanisms and gender have been clearly portrayed in this study focusing on the vulnerabilities and gender sensitivity as a tool for DRR.

For further studies, and the contribution to knowledge, this study establishes a gender gap between societies. Further study could look at the effectiveness of these coping mechanisms whilst maintaining the gender attribute. In Eswatini, DRR is a new field of knowledge; further research can look at expanding this domain. The study has thus alluded to a gendered culture existing in Eswatini and the need to expend the gender lenses of understanding disaster impact in the country. Analysing the coping mechanisms 
during a drought has surfaced the need to acknowledge disparities amongst men and women, disadvantages and vulnerabilities during disasters. This understanding informs decisions made and reasons behind chosen coping mechanisms. Therefore, integrating gender equality into legislation and practice remain as a critical stepping stone towards building a gender-sensitive environment. The integration of international protocols into the operations of all activities is a key recommendation as this will allow good practices to be observed such as gender mainstreaming.

\section{Acknowledgements}

The authors acknowledge the kind respondents from the research area for assisting them in finding some answers as to how they perceive and cope with drought.

\section{Competing interests}

The authors declare that they have no financial or personal relationships that may have inappropriately influenced them in writing this research article.

\section{Authors' contributions}

S.M. adapted the article from a Master's thesis. G.J.W. was the supervisor.

\section{Ethical considerations}

Ethical clearance was not needed or required for the study but followed all ethical standards for carrying out research.

\section{Funding information}

This research received no specific grant from any funding agency in the public, commercial or not-for-profit sectors.

\section{Data availability statement}

The authors confirm that the data supporting the findings of this study are available within the article.

\section{Disclaimer}

The views and opinions expressed in this article are those of the authors and do not necessarily reflect the official policy or position of any affiliated agency of the authors.

\section{References}

1. De la Fuente A, Dercon S. Background paper for the 2009 ISDR Global Assessment Report on disaster risk reduction [homepage on the Internet]. 2008 [cited 2017 Mar 14]. Available from: https://www.preventionweb.net/english/... papers/.../Fuente-and-dercon-nov-08.doc

2. Masih I, Maskey S, Mussá FEF, Trambauer P. A review of droughts on the African continent: A geospatial and long-term perspective. Hydrol Earth Syst Sci. 2014;18(9):3635-3649. https://doi.org/10.5194/hess-18-3635-2014

3. Nyandiko N. Training package on natural hazards and early warning for training of trainers' in Kenya [homepage on the Internet]. 2014 [cited 2016 May 21] Available from: https://www.preventionweb.net/files/26448_26445trainingpack ageonnaturalhazard.pdf

4. Masson V, Norton A, Wilkinson E. Gender and resilience [homepage on the Internet]. 2015 [cited 2016 April 02]. Available from: https://www.odi.org/ publications/9809-gender-and-resilience
5. Mulugeta G, Ayonghe S, Daby D, et al. Natural and human-induced hazards and disasters in sub-Saharan Africa [homepage on the Internet]. 2007 [cited 2016 May 23]. Available from: https://www.fanrpan.org/archive/documents/d00447/ICSU 23]. Available from: https://www.fanrpan.

6. UNISDR (United Nations International Strategy for Disaster Reduction). Terminology [homepage on the Internet]. 2009 [cited 2017 May 25]. Available from: https://www.unisdr.org/we/inform/terminology

7. Mata-Lima H, Alvino-Borba A, Pinheiro A, Mata-Lina A, Almeida JA. Impacts of natural disasters on environmental and socio-economic systems: What makes the difference? Ambient Soc. 2013;16(3):45-64. https://doi.org/10.1590/S1414753X2013000300004

8. Singh K. Application of pressure and release (PAR) model for assessing vulnerability to industrial hazards in district Bathinda (Punjab, India). Int J Manage Soc Sci Res. 2014;3(5):25-29.

9. Wawire VK. Gender and the social and economic impact of drought on the residents of Turkana district in Kenya [homepage on the Internet]. Gender Issues Research Report Series. 2011 [cited 2016 July 17]. Available from: http://ir-library. ku.ac.ke/handle/123456789/12264

10. Rouault M, Richard Y. Intensity and spatial extension of drought in South Africa at different time scales. Water SA. 2003;29(4):489-500. https://doi.org/10.4314/ wsa.v29i4.5057

11. Stringer L, Dyer J, Reed M, Dougil A, Twyman C, Mkwambisi D. Adaptation to climate change, drought and desertification: Local insight to enhance policy in southern Africa. Environ Sci Policy. 2009;12(1):748-765.

12. UN-Habitat. Annual report 2010 [homepage on the Internet]. 2010 [cited 2016 May 21]. Available from: http://unhabitat.org/un-habitat-annual-report-2010/

13. Shongwe $P$, Masuku MB, Manyatsi A. Factors influencing the choice of climate adaptation strategies by households: A case of Mpolojeni area development programme in Swaziland. J Agric Stud. 2014;2(1):86-93.

14. Manyatsi AM, Mhazo N, Masarirambi MT. Climate variability and change as perceived by rural communities in Swaziland. Res J Environ Earth Sci. 2010;2(3):165-170.

15. SVAC (Swaziland Vulnerability Assessment Committee). Swaziland annual vulnerability assessment and analysis [homepage on the Internet]. 2016 [cited 2017 Sep 30]. Available from: http://documents.wfp.org/stellent/groups/public/ documents/ena/wfp286710.pdf

16. Le Masson V, Norton A, Wilkinson E. Gender and resilience [homepage on the Internet]. BRACED; 2015 [cited 2017 Apr 20]. Available from: from www.odi.org/ sites/odi.org.uk/files/odi-assets/publicationsopinion-files/9890.pdf

17. Nhleko JM. Permanent mission of the Kingdom of Swaziland to the United Nations [homepage on the Internet]. In 53rd session of the commission on the status of women, New York, 09 March 2009. 2009 [cited 2016 Jul 16]. Available from: www. un.org/womenwatch/daw/csw/csw53/statements_missions/Swazilan.pdf

18. Dlamini T. Swaziland Economic Policy Analysis and Research Centre (SEPARC): Climate change and women in Swaziland [homepage on the Internet]. 2017 [cited 2017 Sep 07]. Available from: http://www.separc.co.sz/?p=419

19. Glover R, Nyanganyura D. Natural and human induced hazards and disasters [homepage on the Internet]. 2017 [cited 2019 Mar 12]. Available from: https://council.science/cms/2017/05/ICSU-ROA-Science-Plan-Hazards-andhttps://council
Disasters.pdf

20. UNDP (United Nations Development Programme) Gender and disaster [homepage on the Internet]. 2003 [cited 2017 Apr 17]. Available from: http:// www.undp.org/content/dam/undp/library/crisis\%20prevention/ www.undp.org/content/dam/undp/library/crisis\%
disaster/7Disaster\%20Risk\%20Reduction\%20-\%20Gender.pdf

21. Mlenga DH. Drought disaster risk reduction through agriculture development, the role of appropriate technology transfer: Experiences from Swaziland. J Environ role of appropriate techno
Earth Sci. 2015;5(10):8-16.

22. Mabuza K. Swaziland drought assessment report: Rapid assessment 2015/16 season [homepage on the Internet]. 2016 [cited 2016 Jul 18]. Available from: https://www. google.com/url?sa=t\&rct=i\& $=\&$ esrc=s\&source=web\&cd=1\&cad=rj https://www.google.com/url?sa=t\&rct=j\&q=\&esrc=s\&source=web\&cd=1\&cad=rj a\&uact $=8 \&$ ved $=0$ ahUKEwi 1 NOTxKfOAhUICcAKHVYoBvkQFggeMAA\&url=http $\% 3$
$\mathrm{~A} \% 2 \mathrm{~F} \% 2 \mathrm{Fw} w$ w.un.org $\% 2 \mathrm{Fw}$ omenwatch $\% 2 \mathrm{Fdaw} \% 2 \mathrm{Fcsw} \% 2 \mathrm{Fcsw} 53 \% 2 \mathrm{Fstateme}$ nts_missions\%2FSwazilan.pdf\&usg=AFQjCNFIOm4eTIE2Av4p_ShsgdCaT3C2w

23. UNDP (United Nations Development Programme). About Swaziland [homepage on the Internet]. 2012 [cited 2016 Jul 22]. Available from: http://www.sz.undp. org/content/swaziland/en/home/countryinfo.html

24. Vilane B, Mnanyatsi A, Shabangu K. Drought coping strategies at Lonhlupheko community, a semi-arid rural area in Swaziland. Afr J Agric Res. 2015;10(8):783788. https://doi.org/10.5897/AJAR2013.7658

25. Dlamini B. Ministry of Tinkhundla Administration [homepage on the Internet]. 2016 [cited 2016 Jul 20]. Available from: http://www.gov.sz/index. php?option=com_content\&view=article\&id=505\&/temid $=430$

26. Ministry of Tinkhundla Administration and Development (MTAD). Learn more about your Inkhundla [homepage on the Internet]. 2017 [cited 2017 Sep 21]. Available from: http://www.gov.sz/index.php/learn-about-your-inkhundla

27. Enarson E, Chakrabarti P, editors. Women, gender and disaster: Global issues and initiatives. London: Sage; 2009.

28. Falola T, Jean-Jacques $D$, editors. Africa: An encyclopaedia of culture and society. In Encyclopaedia of culture and society [homepage on the Internet]. 2015 [cited $2016 \mathrm{Jul}$ 24]. Available from: https://books.google.co.za/books?id= YjoVCwAAQBAJ\&pg=PA1166\&lpg=PA1166\&dq=patriarchy+swaziland+and+dro ught\&source=bl\&ots=fKmuV4zrp8\&sig=BeKXMO9SU FcRlinHqQDFdhms4g\&hl ught $\&$ source=bl\&ots=fKmuV4zrp8\&sig=BeKXMOSSU_FcRlinHqQDFdhms4g\&hl
$=$ en $\&$ sa $=X \&$ redir_esc $=y \# v=$ onepage $\& q=$ patriarchy\%20swaziland $\% 20$ and $\% 20$ $=$ en $\&$ sa $=X \&$ redir
drought $\& f=$ false 
29. Marquette CM. Survival strategies among Rural Swazi households: Historical, ecological and social dimensions. Forum Dev Stud. 1997;24(2):307-321. https:// doi.org/10.1080/08039410.1997.9666064

30. Mavuso S, Manyatsi A, Vilane B. Climate change impacts, adaptation and coping strategies at Malindza, a rural semi-arid area in Swaziland. Am J Agric Forest 2015;3(3):86-92. https://doi.org/10.11648/j.ajaf.20150303.14

31. Kettler KM, Skaczkowski GL, Turnhill DA. Farmers' stress and coping in a time of drought. Int J Rural Remote Health Res Educ Pract Policy. 2012;12(4):1-16.

32. FAO (Food and Agriculture Organization of the United Nations). A genderresponsive approach to disaster risk reduction (DRR) planning in the agriculture sector: Guidance for supporting rural women and men to build resilience in the face of disasters [homepage on the Internet]. 2016 [cited 2017 Sep 25]. Available from: http://www.fao.org/3/a-i6531e.pdf.y

33. Fordham M, Gupta S, Akerkar S, Scharf M. Leading resilient development Grassroots women priorities, practices and innovation [homepage on the Internet]. 2011 [cited 2017 Oct 02]. Available from: http://www.undp.org/ content/dam/aplaws/publication/en/publications/womens-empowerment/ content/dam/aplaws/publication/en/publications/womens-empowerment/ innovations/f2_GROOTS_Web.pdf

34. Gray C, Mueller V. Drought and population mobility in rural Ethiopia. World Dev. 2012;40(1):134-145. https://doi.org/10.1016/j.worlddev.2011.05.023

35. Stanke C, Kerac M, Prudhomme C, Medlock J, Murray V. Health effects of drought: A systematic review of the evidence. PLoS Curr. 2013;5(1). https://doi. org/10.1371/currents.dis.7a2cee9e980f91ad7697b570bcc4b004

36. Wanders N, Wada Y, Van Lanen A. Global hydrological droughts in the 21st century under a changing hydrological regime. Earth Syst Dyn. 2015;6:1-15. https://doi. org/10.5194/esd-6-1-2015

37. Wolfram S, Lobell D. Robust negative impacts of climate change on African agriculture. Environ Res Lett. 2010;5:1-9. https://doi.org/10.1088/1748 9326/5/1/014010/pdf

38. Wilhite DA, Buchanan M. Drought as hazard: Understanding the natural and social context. In: Wilhite DA, editor. Drought and water crisis: Science, technology, and management issues. New York, NY: Taylor \& Francis, 2005; p. 3-28.

39. Hart C, Berry H, Tonna A. Improving the mental health of rural New South Wales communities facing drought and other adversities. Aust J Rural Health 2011;19(5):231-238. https://doi.org/10.1111/j.1440-1584.2011.01225.x

40. Eiser JR, Bostrom A, Burton I, et al. Risk interpretation and action: A conceptual framework for responses to natural hazards. Int J Disaster Risk Reduct. 2012;1:516. https://doi.org/10.1016/j.ijdrr.2012.05.002

41. Kais SM, Islam MS. Community capitals as community resilience to climate change: Conceptual connections. Int J Environ Res Public Health. 2016;13(12):1211. https://doi.org/10.3390/ijerph13121211

42. Wisner B, Gaillard JC, Kelman I. Handbook of hazards and disaster risk reduction and management. New York, NY: Routledge; 2012.

43. UNISDR (United Nations International Strategy for Disaster Reduction) Environmental protection and disaster risk reduction. A Community Leader's Guide [homepage on the Internet]. Volume 1, issue 1. 2004 [cited 2017 May 17]; Guide [homepage on the Internet]. Volume 1, issue 1. 2004 [cited 2017 May 17];
p. 1-56. Available from: https://www.gdrc.org/uem/disasters/disenvi/ p. 1-56. Available from:

44. Gaillard JC. Vulnerability, capacity and resilience: Perspectives for climate and development policy. J Int Dev. 2010;22(2):218-232. https://doi.org/10.1002/jid.1675

45. Davies M, Guenther B, Leavy J, Mitchell T, Tanner T. Climate change adaptation, disaster Risk Reduction and social protection: Complementary roles in agriculture and rural growth? Working Paper, Centre for Social Protection and Climate Change and rural growth? Working Paper, Centre for Social Protection and Climate Chan

46. Ammann W, Dannenmann S, Vulliet L, editors. Coping with risk due to natural hazards in the 21st century. London: Taylor \& Francis; 2006.

47. Krüger E, Bankoff G, Cannon T, Orlowski B, Schipper E, editors. Cultures and disasters: Understanding cultural framings in disaster risk reduction. Oxford: Routledge; 2015.

48. Eriksen SH, Brown K, Kelly PM. The dynamics of vulnerability: Locating coping strategies in Kenya and Tanzania. Geogr J. 2005;171(4):287-305. https://doi. org/10.1111/j.1475-4959.2005.00174.x
49. Opiyo F, Wasonga O, Nyangito $M$, Schilling J. Drought adaptation and coping strategies among the Turkana Pastoralists of Northern Kenya. Int J Disaster Risk Stri. 2015;6(3):295-309. https://doi.org/10.1007/s13753-015-0063-4

50. Nelson V. Gender, generations, social protection \& climate change [homepage on the Internet]. JOUR; 2011 [cited 2017 Sep 21]. Available from: http://www.nri. org/images/documents/news2011/gender-generations-social-protectionclimatechange.pdf

51. Ashraf MA, Azad MAK. Gender issues in disaster: Understanding the relationships of vulnerability, preparedness and capacity. Environ Ecol Res. 2015;3(5):136-142. https://doi.org/10.13189/eer.2015.030504

52. Hummell B, Cutter S, Emrich C. Social vulnerability to natural hazards in Brazil. Int J Risk Sci. 2016;7(2):111-122. https://doi.org/10.1007/s13753-016-0090-9

53. Eckert $\mathrm{P}$, McConnell-Ginet $\mathrm{S}$. Communities of practice: Where language, gender and power all live [homepage on the Internet]. 2012 [cited 2017 Oct 15]. Available from: http://web.stanford.edu/ eckert/PDF/Communitiesof.pdf

54. UNESCO (United Nations Educational, Scientific and Cultural Organization). Gender sensitivity [homepage on the Internet]. 2000 [cited 2017 Oct 15]. Available from: http://www.unesco.org/education/mebam/module_5.pdf

55. FAO (Food and Agriculture Organisation of the United Nations). Gender responsive disaster risk reduction in the agriculture sector: Guidance for policy makers and disaster risk reduction in the agriculture sector: Guidance for policy makers and
practitioners [homepage on the Internet]. 2016 [cited 2019 Mar 12]. Available practitioners [homepage on the Internet]
from: http://www.fao.org/3/b-i6096e.pdf

56. Crespi I. Socialization and gender roles within the family: A study of adolescents and their parents in Great Britain. Milan: Catholic University of Milan; 2003.

57. Creswell JW. A concise introduction to mixed methods research. Thousand Oaks, CA: Sage; 2015.

58. Creswell JW, Clark VLP. Designing and conducting mixed methods research. 2nd ed. Los Angeles, CA: Sage; 2011.

59. Johnson BR, Christensen L. Educational research: Quantitative, qualitative and mixed approaches. 5th ed. Los Angeles, CA: Sage; 2014.

60. Taylor JG, Stewart TR, Downton M. Perceptions of drought in the Ogallala aquifer region. Environ Behav. 1988;20(2):150-175. https://doi.org/10.1177/ 0013916588202002

61. Dessai S, Sims, C. Public perception of drought and climate change in southeast England. Environ Hazards. 2010;9(4):340-357. https://doi.org/10.3763/ehaz. 2010.0037

62. National Drought Mitigation Centre (NDMC). Types of drought impacts [homepage on the Internet]. 2016 [cited 2016 Nov 09]. Available from: http://drought.unl. edu/DroughtforKids/HowDoesDroughtAffectOurLives/typesofdroughtimpacts. edu/Dro

63. Tadesse D. The impact of climate change in Africa [homepage on the Internet]. ISS paper 220. 2010 [cited 2017 Oct 04]. Available from: https://www.africaportal. org/documents/2753/Paper220.pdf

64. Kreimer A, Arnold M, editors. Managing disaster risk in emerging economies. Washington, DC: World Bank; 2000.

65. Myeong S, Seo $\mathrm{H}$. Which type of social capital matters for building trust in government? Looking for a new type of social capital in the governance era, Sustainability. 2016;8(322):1-15. https://doi.org/10.3390/su8040322

66. Wisner B, Blaikie P, Cannon T, Davis I. At risk: Natural hazards, people's vulnerability and disasters. 2nd ed. London: Routledge; 2004.

67. FAO (Food and Agriculture Organization of the United Nations). Training guide gender and climate change research in agriculture and food security for rural gender and climate change research in agriculture and food security for rura from: http://www.fao.org/sustainable-forest-management/toolbox/tools/toolfrom: http://www.

68. Constitution of Swaziland. The constitution of the Kingdom of Swaziland Act 2005 Mbabane: Government Printer; 2005.

69. Gaoutte N. U.S. dispatches emergency aid for Ethiopian drought [homepage on the Internet]. 2016 [cited 2017 Oct 16]. Available from: https://edition.cnn. $\mathrm{com} / 2016 / 03 / 03 /$ politics/ethiopia-us-disaster-assistance-drought/index.html

70. Enfors E, Gordon L. Dealing with drought: The challenge of using water system technologies to break dryland poverty traps. Global Environ Change. 2008;18(4):606-616. https://doi.org/10.1016/j.gloenvcha.2008.07.006 